\title{
Surgical Treatment of Upper Gastrointestinal Tract Crohn Disease: A Long Way to Go to Identify the Optimal Method
}

\author{
Soo Yeun Park \\ Colorectal Cancer Center, Kyungpook National University Chilgok Hospital, School of Medicine, Kyungpook National University, Daegu, \\ Korea
}

\section{See Articles on Page 243-248}

Crohn disease (CD) is one of the 2 main categories of chronic inflammatory bowel disease. $\mathrm{CD}$ has a multifactorial etiology of genetic factors, malfunction of the immune system, gut bacteria dysbiosis, and environmental factors [1]. The incidence of CD in Korea has steadily risen during the past few decades from 0.2 per 100,000 between 1991 and 1995, to 0.5 per 100,000 between 1996 and 2000, 1.3 per 100,000 between 2001 and 2005 [2], and 3.2 per 100,000 between 2006 and 2012 [3]. Furthermore, the prevalence of $\mathrm{CD}$ in Korea increased by about 2-fold from 16.0 per 100,000 in 2009 to 29.6 per 100,000 in 2016.

$\mathrm{CD}$ is a heterogeneous disorder that can affect any part of the gastrointestinal tract from the oral cavity to the anus [4, 5]. Although routine gastrointestinal endoscopy identified microscopic inflammation in up to $60 \%$ of patients with $\mathrm{CD}$ in western countries, and mucosal alterations were found in $70 \%$ of patients being treated for $\mathrm{CD}$ in a Korean tertiary hospital, symptomatic involvement of the upper gastrointestinal tract (UGI) is uncommon and only occurs in $0.3 \%$ to $5 \%$ of adult patients with $\mathrm{CD}[6,7]$. The common symptoms of UGI CD are abdominal pain, distension, nausea, vomiting, diarrhea, anemia, and weight loss. UGI CD is initially managed with medical treatment comprising anti-inflammatory and antacid agents, but has a high risk of complications such as stricture, ulceration, obstruction, and fistula. Surgical treatment remains the mainstay for patients with $\mathrm{CD}$ with ongo-

Correspondence to: Soo Yeun Park, M.D.

Colorectal Cancer Center, Kyungpook National University Chilgok Hospital, School of Medicine, Kyungpook National University, 807 Hoguk-ro, Buk-gu, Daegu 41404, Korea

Tel: +82-53-200-2166, Fax: +82-53-421-0510

E-mail: psy-flower@daum.net

ORCID: https://orcid.org/0000-0003-4821-2101

(C) 2020 The Korean Society of Coloproctology

This is an open-access article distributed under the terms of the Creative Commons Attribution NonCommercial License (https://creativecommons.org/licenses/by-nc/4.0) which permits unrestricted noncommercial use, distribution, and reproduction in any medium, provided the original work is properly cited. ing symptoms or complicated disease. The bowel resection rates for Korean patients with $\mathrm{CD}$ are $5.0 \%$ and $9.1 \%$ at 1 and 5 years after diagnosis, respectively [3]. The mean number of surgeries performed for CD in Korea was 791.8 per year from January 2009 to October 2016 [8]. However, information regarding surgery for UGI CD is sparse and has not been reported for patients with CD in Korea.

Moon et al. [9] analyzed the outcomes of adult patients who underwent surgery for UGI CD during a 20 -year period at a single institution. The perioperative outcomes of 24 patients $(2.96 \%$ of the total cohort) who underwent surgery for UGI CD were compared with those of 787 patients (97.04\% of the total cohort) with only distal $\mathrm{CD}$. Compared with patients who underwent surgery for distal CD, patients who underwent surgery for UGI CD had a higher prevalence of concomitant procedures, longer hospital stay, and higher prevalence of postoperative complications. Most patients achieved good outcomes after bypass surgery and/or primary repair. In contrast to previous studies that reported that the most common surgical indication for patients with $\mathrm{CD}$ was obstruction [10], 58.3\% of the patients in the study by Moon et al. [9] underwent surgery for penetrating fistula. Half of the patients with a fistula might have had penetration of distal CD such as the ileum or transverse colon. Another half of the patients with a fistula were considered to have a primary gastroduodenal fistula caused by $\mathrm{CD}$, and the incidence ( $0.86 \%$ of the total cohort) of primary fistula was similar to that reported in a previous study (less than 1\%) [5]. Patients with penetrating fistula had a prolonged hospital stay and higher prevalence of postoperative complications compared with those with obstruction. Overall, the 5 -year recurrence rate after surgical treatment of UGI was 5\% to $8 \%$ [11]. Although the authors did not perform strictureplasty, this may be a valuable option for selected patients with obstructive gastroduodenal CD [12, 13]. Moreover, prior to considering surgery, endoscopic intervention (balloon dilatation with or without corticosteroid injection) may be a good treatment for obstructive lesions in selected patients with UGI CD [14].

An increasing amount of evidences shows that the laparoscopic approach for CD of both lower gastrointestinal tract and the UGI 
improves the postoperative recovery and cosmetic results. Thus, the recent European Crohn and Colitis Organization guidelines recommend the laparoscopic approach for $\mathrm{CD}$ surgery when feasible [15]. As UGI CD is frequently associated with ileal or colonic lesions and a history of previous surgery, Moon et al. [9] only used the laparoscopic approach in one patient with UGI CD. Gastrojejunostomy bypass is the procedure that is best suited to the laparoscopic approach for UGI CD, and laparoscopic gastrojejunostomy for duodenal CD was first reported in 1996 [16]. Another study reported that patients who underwent laparoscopic bypass for duodenal $\mathrm{CD}$ experienced an early recovery with a similar recurrence rate to those who underwent open bypass for duodenal CD [17].

The medical and surgical management of $\mathrm{CD}$ has undergone remarkable advancements due to extensive studies and drug development. The number of surgical cases has decreased due to the introduction of various new drugs. Nonetheless, the idiopathic chronic nature of $\mathrm{CD}$ remains largely changeable, and surgery is required in cases with intractable symptoms or complications. The surgical treatment of UGI CD is challenging because of the rarity of such cases and the limited amount of available evidences. Furthermore, there is no clear consensus regarding the optimal surgery. UGI CD in Korean patients may be different from that in other countries. Many recent studies have evaluated the characteristics and clinical course of Korean patients with CD using multicenter or national databases. Considering the severe and complicated nature of UGI CD, there is a need for further studies evaluating multicenter or nationwide data on the surgical treatment of UGI CD to enable the successful surgical treatment of individual patients with this lifelong disease.

\section{CONFLICT OF INTEREST}

No potential conflicts of interest relevant to this article were reported.

\section{REFERENCES}

1. Strober W, Fuss I, Mannon P. The fundamental basis of inflammatory bowel disease. J Clin Invest 2007;117:514-21.

2. Yang SK, Yun S, Kim JH, Park JY, Kim HY, Kim YH, et al. Epidemiology of inflammatory bowel disease in the Songpa-Kangdong district, Seoul, Korea, 1986-2005: a KASID study. Inflamm Bowel Dis 2008;14:542-9.

3. Kim HJ, Hann HJ, Hong SN, Kim KH, Ahn IM, Song JY, et al. Incidence and natural course of inflammatory bowel disease in Korea, 2006-2012: a nationwide population-based study. Inflamm
Bowel Dis 2015;21:623-30.

4. Crohn BB, Ginzburg L, Oppenheimer GD. Landmark article Oct 15, 1932. Regional ileitis: a pathological and clinical entity. By Burril B. Crohn, Leon Ginzburg, and Gordon D. Oppenheimer. JAMA 1984;251:73-9.

5. Reynolds HL Jr, Stellato TA. Crohn's disease of the foregut. Surg Clin North Am 2001;81:117-35.

6. Pimentel AM, Rocha R, Santana GO. Crohn's disease of esophagus, stomach and duodenum. World J Gastrointest Pharmacol Ther 2019;10:35-49.

7. Joung YH, Lee DG, Kim HJ, Kim YW, Lee BO, Han YS, et al. Crohn's disease of the upper gastrointestinal tract: endoscopic and histologic characteristics and prevalence of Helicobacter pylori infection. Korean J Gastrointest Endosc 2003;27:1-9.

8. Baek SJ, Lee KY, Song KH, Yu CS. Current status and trends in inflammatory bowel disease surgery in Korea: analysis of data in a nationwide registry. Ann Coloproctol 2018;34:299-305.

9. Moon JS, Lee JL, Yu CS, Lim SB, Park IJ, Yoon YS, et al. Clinical characteristics and postoperative outcomes of patients presenting with upper gastrointestinal tract Crohn disease. Ann Coloproctol 2020;36: 243-8.

10. Schwartzberg DM, Brandstetter S, Grucela AL. Crohn's disease of the esophagus, duodenum, and stomach. Clin Colon Rectal Surg 2019;32:231-42.

11. Dolgin SE. Surgical management of upper gastrointestinal and small bowel Crohn's disease. Semin Pediatr Surg 2007;16:172-7.

12. Singh A, Agrawal N, Kurada S, Lopez R, Kessler H, Philpott J, et al. Efficacy, safety, and long-term outcome of serial endoscopic balloon dilation for upper gastrointestinal Crohn's disease-associated strictures: a cohort study. J Crohns Colitis 2017;11:1044-51.

13. Sampietro GM, Cristaldi M, Maconi G, Parente F, Sartani A, Ardizzone S, et al. A prospective, longitudinal study of nonconventional strictureplasty in Crohn's disease. J Am Coll Surg 2004;199: 8-22.

14. Guo F, Huang Y, Zhu W, Wang Z, Cao L, Chen A, et al. Efficacy and safety of endoscopic balloon dilation for upper gastrointestinal strictures of Crohn's disease. Dig Dis Sci 2016;61:2977-85.

15. Bemelman WA, Warusavitarne J, Sampietro GM, Serclova Z, Zmora O, Luglio G, et al. ECCO-ESCP consensus on surgery for Crohn's disease. J Crohns Colitis 2018;12:1-16.

16. Reissman P, Salky BA, Pfeifer J, Edye M, Jagelman DG, Wexner SD. Laparoscopic surgery in the management of inflammatory bowel disease. Am J Surg 1996;171:47-51.

17. Shapiro M, Greenstein AJ, Byrn J, Corona J, Greenstein AJ, Salky $B$, et al. Surgical management and outcomes of patients with duodenal Crohn's disease. J Am Coll Surg 2008;207:36-42. 